\title{
Awareness, Knowledge and Practice of Breast-Self Examination amongst Female Health Workers in A Nigerian Community.
}

\author{
Omolase Charles Oluwole ${ }^{1}$
}

\begin{abstract}
AIM : This study was designed to assess the awareness, knowledge and practice of breast-self examination amongst female health practitioners at Federal Medical Centre, Owo, Ondo State, Nigeria.

METHODOLOGY : This study was conducted in the month of February,2008. One hundred health workers practicing in the hospital were selected by simple random sampling and interviewed with the aid of structured questionnaire by the author.

Informed consent was obtained from each of the respondents. The information obtained included bio data of the respondents, awareness, knowledge and the practice of breast-self examination. The data obtained was collated and analyzed by SPSS soft ware version 12.0.1.

RESULTS: Most respondents (94\%) were aware of breast-self examination. Some of them (30\%) knew the different methods for screening for breast cancer, however most of them $(56 \%)$ knew that breast-self examination should be performed monthly. Majority of the respondents $(80 \%)$ practiced breast-self examination even though only some (50\%) practiced it monthly.

CONCLUSION: Majority of the respondents were aware of breast-self examination. Knowledge about screening methods for breast cancer was poor.

The practice of breast - self examination amongst females should be encouraged.
\end{abstract}

Key words: Breast, cancer, examination, awareness, knowledge and practice.

$\mathrm{B}$ reast cancer is the leading cause of cancer related deaths among women worldwide $^{1-3}$. Diagnosis of breast cancer at an earlier stage allows women more treatment choices and greater chance of long term survival ${ }^{4,5}$. In a bid to reduce the incidence of mortality from breast cancer there is need for an effective screening program. Empowering female health workers and creating awareness amongst them could go a long way in enhancing the screening program for breast cancer. Prevention or identification of breast cancer at an early stage is of paramount importance in saving lives as well as improving the quality of life ${ }^{6}$. Breast cancer lends itself to early detection and subsequent early treatment if women use early detection measures ${ }^{7}$.

$\overline{\text { 1. Department Of Ophthalmology, Federal Medical }}$ Centre,Owo. Ondo State. Email address : omolash2000@yahoo.com.
The three screening methods recommended for breast cancer include breast-self examination (BSE), clinical breast examination (CBE) and mammography ${ }^{8}$. It is important to adequately motivate women to regularly carry out BSE so as to curtail the increasing mortality rate from breast cancer. Although the role of regular BSE has been debated $^{9}$, it can nevertheless be utilized in enhancing breast cancer awareness among women $^{6}$. In fact regular BSE has been suggested as part of overall health promotion concept $^{10}$. The practice of BSE can help women to know the structure and composition of their normal breast thereby enhancing their sensitivity to detect any abnormality at the earliest time.

BSE once a month contributes to a woman's heightened awareness of what is normal for her $^{11}$. It is recommended that women over the age of 20 years perform a monthly BSE to detect new lumps and other changes in their breast. Changes in the behavior of women and 
physicians are needed to increase the use of BSE, clinical breast examination and mammographic screening ${ }^{12}$.

In view of the fact that mammography is not readily available in our own environment, this study was designed to assess the awareness ,knowledge and practice of regular BSE amongst female health workers at Federal Medical Centre, Owo so as to draw relevant policy implications from this study.

\section{Methodology}

This study was conducted at Federal Medical Centre, Owo, Ondo State, Nigeria in February 2008. Ethical clearance was obtained from the Ethical committee of the hospital prior to commencement of this study. One hundred consenting female health workers were selected by simple random sampling out of one hundred and seventy eight practicing in the hospital. The respondents were interviewed with the aid of structured questionnaire by the author. Information obtained included bio data of the respondents, awareness about BSE, source of awareness, knowledge and practice of BSE. The respondents were also asked about past history of benign breast disease and family history of breast cancer. The data obtained was collated and analyzed with the aid of SPSS soft ware version12.0.1.

\section{Results}

One hundred respondents were interviewed. Their ages ranged from 23 years to 50 years with a mean age of 33 years. Some (42\%) were single while majority $(58 \%)$ was married. There were 94 Christians and 6 Muslims. None of the respondents practiced traditional religion. As shown in table 1 most respondents were nurses accounting for 55\% while $19 \%$ were medical doctors. The ethnicity of the respondents included Yorubas (84\%), Ibos (7\%) and the other ethnic groups accounted for the remaining $9 \%$.

$30 \%$ had knowledge of the different methods of screening for breast cancer while the remaining ones $(70 \%)$ did not know.

Majority (56\%) of the respondents knew that BSE should be carried out on a monthly basis while the remaining (44\%) did not know.

Table 1 : Occupation of the Respondents

\begin{tabular}{l|cc} 
& & \\
\multicolumn{1}{c|}{ Occupation } & Frequency & Percentage(\%) \\
\hline Medical practitioner & 19 & 19 \\
Nursing & 55 & 55 \\
Pharmacy & 11 & 11 \\
Optometry & 1 & 1 \\
Dental therapy & 1 & 1 \\
Health records & 2 & 2 \\
Laboratory science & 11 & 11 \\
\hline \multicolumn{1}{c}{ Total } & 100 & 100
\end{tabular}

As shown in table 2, majority (54\%) of the respondents became aware of BSE through lectures while $19 \%$ became aware through their colleagues.
Most respondents (80\%) practiced BSE while the rest $(20 \%)$ did not. $40(50 \%)$ practiced BSE as recommended monthly, some: 9 $(11.25 \%)$ practiced it quarterly, others: 
$18(22.5 \%)$ practiced it every six months and the remaining ones practiced it occasionally: $8(10 \%)$ and annually: $5(6.25 \%)$. As shown in table 3 the main identified barriers to practice of BSE were lack of information (40\%) and forgetfulness $(26 \%)$.

Majority of the respondents( $92 \%$ ) considered BSE effective.
Only $30 \%$ had breast examination done by a medical doctor while the rest (70\%) never had clinical breast examination.

Very few respondents (10\%) admitted to history of benign breast disease while the majority $(90 \%)$ did not.

Only three of the respondents admitted to family history of breast cancer.

\section{Table 2 : Sources of awareness about breast-self examination}

\begin{tabular}{l|cc} 
Source & Frequency & Percentage(\%) \\
& & \\
Colleague & 19 & 20.2 \\
Media & 9 & 9.6 \\
Internet & 4 & 4.3 \\
Lecture & 54 & 57.4 \\
Books & 6 & 6.4 \\
Family members & 1 & 1.1 \\
Friends & 1 & 1.4 \\
& & \\
\hline & & 100
\end{tabular}

Table 3 : Barriers to practice of breast-self examination

\begin{tabular}{l|cc} 
& & \\
Barriers & Frequency & Percentage(\%) \\
\hline Lack of information & 40 & $41.2 \%$ \\
Don't see the need & 9 & 9.3 \\
Anxiety & 9 & 9.3 \\
Forgetfulness & 26 & 26.3 \\
Absence of symptoms & 6 & 6.2 \\
Pressure of work & 2 & 2.1 \\
Not convinced about effectiveness & 2 & 2.1 \\
& & \\
\hline & & 100
\end{tabular}

\section{Discussion}

The age range of the respondents falls within what is expected of civil service that they belong to. One is not surprised that an overwhelming majority of the respondents were Yorubas, this is in keeping with the fact that the study community is a Yoruba community. Most respondents were
Christians; this is also in tandem with the predominant religion in the community. The fact that all the cadres of the core health professionals participated in this study also helped in minimizing cadre related bias in this study. It is quite impressive that majority of the respondents were aware of BSE. This finding is even more reassuring considering 
the fact that the respondents as health workers could help in creating awareness about BSE amongst their patients. The level of awareness in this study population about BSE is also consistent with that of another Nigerian study in which the level of awareness was $84.6 \%$. ${ }^{13}$ The uptake of clinical breast examination in this study even though low; is higher than that of Onwere et al in Aba, Nigeria in which only $1 \%$ and $2 \%$ of their respondents had clinical breast examination performed by doctors and nurses respectively. ${ }^{14}$

The majority of the respondents practiced BSE, but only some of them practiced it monthly. In a similar study Mbanaso et al. found that $84 \%$ of their study population practiced BSE, however only $47.9 \%$ of them performed it monthly. ${ }^{15}$ The finding of this study is however higher than that of an Iranian and Egyptian study though not amongst health workers in which only $6 \%$ and $2.65 \%$ of the study population respectively practiced BSE monthly. ${ }^{16,17}$

Sadler et al reported in a study carried out in America that $31 \%$ of their study population practiced BSE monthly. ${ }^{18}$

As in this study, majority of the respondents $(86.4 \%)$ in another Nigerian population considered BSE an effective way of detecting breast cancer. ${ }^{15}$

About a third of the respondents knew about the different methods for detection of breast cancer, this finding is disappointing considering the fact that the respondents were health workers. More than half of the respondents attributed lack of information as a barrier to practice of breast - self examination. This finding and the later one brings to fore the need to incorporate the methods of detection of breast cancer in the training of the core health professionals.

\section{Conclusion And Recommendation}

Majority of the respondents were aware of BSE, however their sources of awareness varied. The knowledge about the different methods of screening of breast cancer was generally poor.
Most respondents practiced BSE although less than half of them performed it on the recommended monthly basis.

\section{Recommendation}

1) There is need to create awareness about the importance of BSE amongst women so as to improve this practice of in a bid to detect breast cancer at an early stage.

2) Screening methods for breast cancer should be included in the curricula of health professionals so as to empower them to take up the challenge of breast cancer detection.

3) Medical doctors should pay more attention to clinical breast examination especially where there are identified risk factors.

4) Mammography should be made more readily available in Nigeria.

5) Similar studies should be done amongst non-health practitioners preferably in a rural setting.

\section{Acknowledgement}

I appreciate the respondents for graciously accepting to participate in this study. The support of the management of Federal Medical Centre, Owo is hereby acknowledged. Finally I glorify God for the strength and insight to carry out this study.

\section{References}

1. Jemal A, Siegel R, Ward E, et al. Cancer statistics 2006. CA . A Cancer J Clin 2005;56:106-130.

2. Anderson BO, Shyyan R, Eniu A, et al . Breast cancer in limited-resource countries : An overview of the Breast Health Global Initiative 2005 Guidelines. Breast J 2006;12: 3-15.

3. Groot MT ,Battussen R, Uyl-de Groot CA, et al. Costs and health effects of breast cancer interventions in epidemiologically different regions of Africa,North America and Asia. Breast J 2006;12: 81-90.

4. Chong PN, Krishnan M ,Hong CY, et al. Knowledge and practice of breast cancer screening amongst public health nurses in Singapore. Singapore Med J 2002;43:509-516. 


\section{Omolase Charles Oluwole}

5. American Cancer Society ,.Breast cancer facts and figures 2005-2006. American cancer society Inc Atlanta 2005.

6. Rao RSP, Nair S, Nair NS et al. Acceptability and effectiveness of breast health awareness programme for rural women in India. India J Med Sci 2005;59: 398402.

7. Abimbola OO. Rural women's perception of breast cancer and it's early detection measures in Ibadan, Nigeria. Cancer Nursing 2006;29(6): 461-466.

8. Okobia $\mathrm{MN}$, Bunker $\mathrm{CH}$, Okonofua $\mathrm{FE}$ et al. Knowledge, attitude and practice of Nigerian women towards breast cancer. A cross-sectional study. World $J$ Surg Oncol.2006; 4:11 16504034.

9. Hackshaw AK, Paulo EA. Breast self examination and death from breast cancer a Meta Analysis. $\mathrm{Br} J$ Cancer 2003; 88:1047-53.

10. Plesnicar A, Kovac V, Kralj B. Breast cancer and breast health awareness as an evolving health promotion concept. Radio Oncol 2004; 38;27-34.

11. Larkin M. Breast self examination does more harm than good, says task force. Lancet 2001;357:21092110 .

12. Mah $\mathrm{Z}$ and Bryant $\mathrm{H}$. Age as a factor in breast cancer knowledge, attitudes and screening behaviours . CMAJ 1992; 146(12):2167-2174.

\section{Practice Of Breast-Self Examination}

13. Oladepo $\mathrm{O}$ and Adegoke F. Breast selfexamination among female students in tertiary institutions in a Nigerian community. International Ouarterly of Community Health Education 1997; 16(2):175-85.

14. Onwere S, Okoro O, Chigbu B et al. Practice of antenatal clinical breast examination as a method of early detection of breast cancer by health care providers in a low resource setting. Archives of Gynecology and Obstetrics 2007;10.10007/s000404007-0533-z(Abstract).

15. Mbanaso AU, Adisa AC, Onuoha C et al .Status of Breast Self Examination among health professional of Abia State University Teaching Hospital. Journal of Experimental and Clinical Anatomy 2005; 4(1):55-57. 16. Haji-Mahmoodi M, Montazeri A, Jarvandi S , et al. Breast self -examination: Knowledge ,attitudes and practices among female health care workers in Tehran Iran. Breast Journal 2002; 8(4):222-225.

17. Abdel-Fattah M, Zaki A, Bassili A, et al. Eastern Meditterranean Health Journal 2000; 6(1):34-40.

18. Sadler GR, Ko CM, Cohn JA, et al. Breast cancer knowledge ,attitudes and screening behaviors among African American women the Black cosmetologists promoting health program. BMC public health 2007;7:57. 